\title{
Las líneas férreas desmanteladas en Andalucía: Diagnóstico para su uso como itinerarios no monotorizados
}

\author{
Miguel GARCÍA MARTÍN \\ Departamento de Geografía Humana \\ Universidad de Sevilla \\ mgmartin@us.es
}

Recibido: 28 de enero de 2014

Enviado a evaluar: 13 de febrero de 2014

Aceptado: 7 de mayo de 2014

\section{RESUMEN}

Las líneas ferroviarias que han dejado de prestar servicio presentan una oportunidad para ser reutilizadas como ejes alternativos para desplazamientos no motorizados (a pie, en bicicleta, a caballo...), en el marco de una política de desarrollo regional y apuesta por actividades turísticas sostenibles, de base rural. Este artículo identifica las vías férreas desmanteladas en Andalucía, para analizar posteriormente su aptitud de uso -es decir, el estado de adecuación para ser transitadas y la accesibilidad a núcleos de población y redes de comunicación- así como las cualidades ambientales y paisajísticas del entorno que atraviesan. De dicho análisis surge una caracterización de cada una de las vías en función de su mayor o menor idoneidad para acoger dichos usos alternativos (capacidad potencial). Dicho diagnóstico podrá orientar los criterios que las distintas administraciones públicas adopten en el desarrollo de políticas de fomento y recuperación de "itinerarios verdes".

Palabras clave: Ferrocarril desmantelado, vía verde, carril bici, desarrollo regional, ecoturismo, patrimonio ferroviario.

\section{Disused railway lines in Andalusia: A diagnostic as traffic-free routes}

\begin{abstract}
Railway lines that are no longer in use have an opportunity to be converted into alternative trafficfree routes -footpaths, cycle lanes...-, as a part of the regional development policy and the support of a sustainable way of tourism. In this paper we identify such former railways lines in Andalusia, and then we analyse the suitability for public use (conditions for the transit and accessibility to urban areas and transport networks). The environmental quality and the surrounding landscape features are also analysed. As a result, we obtain a characterization of each railway line according to the potentiality to be used as a rail trail. Finally, this diagnostic should guide the judgements in the public decision making, within the context of greenway promotion and planning.
\end{abstract}

Key words: Abandoned railway, rail trail, greenway, cycle lane, regional development, ecotourism, heritage railway. 
Les lignes de chemin de fer démantelé en Andalousie:

Pour une utilisation en tant que voies de diagnostic et non des monotorizados

\section{RÉSUMÉ}

Lignes de chemin de fer qui ont quitté le service offre une occasion pour les réutiliser comme axes alternatifs pour non motorisés (marche à pied, vélo, cheval ...), dans le cadre d'une politique de développement régional et de l'engagement pour le tourisme base rurale durable. Cet article identifie les chemins de fer démantelé en Andalousie, la façon d'analyser en utilisant aptitude que signifie le fait d'être occupé et de remise en forme pour l'accessibilité des centres de population et des réseaux de communication, ainsi que des qualités environnementales et paysagères de l'environnement qui traverser. A partir de cette analyse une caractérisation de chacun des trajets en fonction de leur degré de pertinence pour tenir compte de ces autres utilisations (capacité potentielle) se pose. Ce diagnostic peut cibler différents critères à adopter en élaboration de politiques gouvernementales et de la récupération de la construction de "voies vertes".

Mots clés: Chemin de fer démantelé chemin verte cyclable, le développement régional, l'écotourisme, patrimoine ferroviaire.

\section{INTRODUCCIÓN}

Desde finales del siglo XX se viene asistiendo en Andalucía, como en otras regiones de la órbita europea y occidental, al abandono y el desmantelamiento de una parte importante la red convencional de ferrocarril. Ya sea por que finalizaron las actividades vinculadas a este transporte, bien porque son vistos como servicios deficitarios, estas infraestructuras de transporte ofrecen, sin embargo, una oportunidad de desarrollo rural y regional al poder recuperarse e incorporarse como itinerarios no motorizados - de uso turístico o cotidiano-.

Diversas experiencias en países y regiones del mundo desarrollado (García Martín, 2009) ponen de manifiesto la conveniencia de la política de fomento de las vías verdes, apoyada en gran parte sobre la recuperación de trazados ferroviarios abandonados o desmantelados. En el caso español, esta política se viene diseñando desde finales del siglo XX mediante el Programa Vías Verdes de la Fundación de los Ferrocarriles Españoles, que en 2010 ya había recuperado cerca de $1.800 \mathrm{~km}$ de vías verdes repartidos en 80 itinerarios (Observatorio de Caminos Naturales e Itinerarios no Motorizados, 2011: 58).

Este artículo identifica las vías férreas desmanteladas, abandonadas o sin uso en Andalucía, incorporando aquellos trazados que no aparecen en los inventarios elaborados por el Ministerio de Obras Públicas, Transportes y Medio Ambiente (Dirección General de Planificación Territorial, 1995). Para todas ellas se elabora un diagnóstico de uso público partiendo del análisis de su aptitud para el uso (adecuación para el tránsito y accesibilidad), de un lado, y de sus cualidades ambientales y paisajísticas. Dicho diagnóstico pretende poner de manifiesto el mayor o menor grado de oportunidad de las distintas líneas férreas no operativas en la región, muchas de las cuales ya disfrutan de una conveniente función pública como vías verdes acondicionadas, si bien hay otras muchas sobre las que aún no se han proyectado actuaciones públicas de recuperación. 


\section{BREVE ANTECEDENTE HISTÓRICO DEL FERROCARRIL EN ANDALUCÍA}

Previo al análisis de la red ferroviaria sin uso en Andalucía, conviene hacer una breve alusión al origen de sistema ferroviario regional. La primera línea ferroviaria que se construye en Andalucía es la que conecta Jerez con el Puerto de Santa María, en 1854. Sin embargo, la ausencia de un criterio institucional para la planificación y la gestión de los nuevos caminos de hierro que empiezan a diseñarse en España se refleja en la inexistencia de normativa legal al respecto hasta 1855 , año de la primera Ley de Ferrocarriles. Hasta entonces la principal referencia del gobierno ante el surgimiento de nuevas compañías de ferrocarril consistía en el informe de los ingenieros Subercasse y Santa Cruz que orientaba los criterios oficiales frente a la inversión privada y establecía algunas recomendaciones técnicas (el ancho de vía) y de diseño de la estructura de la red ferroviaria nacional (Millán Rincón, 2005).

De la ley de Ferrocarriles de 1855 se pueden destacar aspectos como que las concesiones se otorguen por subasta y que tengan una validez de 99 años, tras lo cual la posesión de la línea pasa al Estado. También se recogen algunos privilegios para la protección de capitales extranjeros ante situaciones de guerra o la obligatoriedad de revisar las tarifas cada 5 años (Ibídem: 39).

En los años siguientes se empieza a desarrollar una red básica estructurante, concentrada en Andalucía occidental, impulsada desde la iniciativa privada. La mayor parte del tráfico de pasajeros se concentra en dos compañías, la Compañía de los ferrocarriles de Madrid a Zaragoza y Alicante (MZA) y la Compañía de los Ferrocarriles Andaluces (“Andaluces”), cuyas líneas conectaban la región con el exterior, así como los principales centros productores - agrícolas, industriales y mineros - con los exportadores - puertos- . Por tanto, la constitución de la red ferroviaria a lo largo del siglo XIX responde más a los intereses privados de transporte de mercancías que al interés público de articulación territorial en su sentido más amplio (Ibídem: 43). Hacia 1880, la red ferroviaria andaluza sirve principalmente de soporte al tráfico de los vinos jerezanos, malagueños y del Condado, el aceite de Jaén y Córdoba, el plomo de Linares y el carbón de Bélmez y Espiel hacia los puertos de Málaga, Cádiz y Sevilla, por donde se movilizaba el carbón, el hierro y el trigo procedente de Europa y los productos textiles de Málaga.

Por otro lado, las principales fuentes de explotación mineral en Andalucía se localizan, a finales del siglo XIX en el norte y en los extremos oriental y occidental de Andalucía, lo que lleva a la construcción de muchas líneas autónomas, que buscan salida al mar, lo que no contribuye a la consolidación de una red organizada e integral. En Huelva, la competencia entre compañías llevó a la construcción de líneas paralelas y alternativas para la salida de los minerales hacia los puertos de Huelva y Sevilla (Morilla Critz, 1999).

En los últimos años del siglo XIX y primeros del siglo XX se abordan las diferentes obras para la construcción de líneas que conectaran Andalucía occidental y oriental. A la consecución de este periodo, la red ferroviaria andaluza acabó integrando, de forma algo precaria, casi todo el territorio regional, por medio de una 
retícula desigualmente distribuída, poco densa y abierta en su extremo sur hacia el litoral. A lo largo del primer tercio del siglo XX, hasta la Guerra Civil, toman protagonismo los ferrocarriles de vía estrecha, tanto los ferrocarriles mineros (aunque de servicio mixto) como los tranvías urbanos e interurbanos y los cables aéreos. (Millán Rincón, 2005).

Tras la Guerra Civil y con la llegada del régimen franquista llega un periodo caracterizado por la intervención por parte del Estado de todas las grandes compañías y la nacionalización y unificación de todas las líneas españolas de vía ancha en una única empresa estatal, la Red Nacional de los Ferrocarriles Españoles, RENFE, creada en 1941. Durante las décadas siguientes se impulsa la modernización y reconstrucción de la red existente y, entre otras medidas, se asiste a la sustitución de las máquinas de vapor por locomotoras diesel y eléctricas. En 1969 existen en España cerca de 13.700 kilómetros de vía ancha de ferrocarril en funcionamiento, siendo ésta la mayor longitud que ha llegado a alcanzar en activo la red ferroviaria española de vía ancha (Dirección General de Planificación Territorial, 1995).

Sin embargo, a raíz del Informe del Banco Internacional de Reconstrucción y Fomento de 1962, que considera que cerca del $80 \%$ de los kilómetros de línea de la red ferroviaria española arrojan coeficientes superiores a $100^{1}$, se inicia una política de clausura de vías deficitarias, que, en Andalucía, afecta a una parte importante de la red. Este informe también recomienda que se paralicen las obras de las líneas en construcción así como que no se proyecten líneas nuevas (Banco Internacional de Reconstrucción y Fomento, 1962). De forma semejante, muchos de los ferrocarriles de vía estrecha, que aún eran explotados por sus respectivas compañías privadas, abandonan durante este periodo su explotación ante el fin de la actividad para la que fueron creados - principalmente la actividad minera - y la competencia del transporte por carretera (Millán Rincón, 2005).

Otro de los momentos clave en el proceso de reducción de líneas de ferrocarril se produce a partir del contrato-programa del Estado y RENFE del periodo 1984-86, que obliga a reducir el déficit económico de empresas de servicios públicos como RENFE, mediante la clausura de líneas y la reducción de plantilla. Así, el Estado considera como deficitarias un total de $3.055 \mathrm{~km}$ de vías, de las que cerca de un $32 \%$ se encuentran en territorio andaluz (Pérez Ramírez, Fuentes Ruiz, 1997; Ramos Melero, 2002). Finalmente, pese al cierre de gran parte de estas líneas, otras muchas mantienen su servicio con el apoyo financiero de los gobiernos autonómicos. De todas formas, a nivel nacional se cierran en 1985 a todo tráfico un total de $914 \mathrm{~km}$ de vías férreas, mientras que se reducen a tráfico de mercancías otros $933 \mathrm{~km}$ (Red Nacional de los Ferrocarriles Españoles, 2007). En Andalucía sobresalen, por su

${ }^{1}$ El coeficiente de explotación se calcula dividiendo los gastos de explotación por los ingresos Un coeficiente de más de 100 significa que los ingresos no alcanzaron a cubrir ni siquiera los costes de explotación. Para que la explotación sea favorable se necesitan coeficientes inferiores a 100, ya que los costes que no son de explotación (depreciación, intereses) deben cubrirse también con los ingresos (Banco Internacional de Reconstrucción y Fomento, 1962). 
longitud, el cierre de las líneas Jaén-Campo Real y Guadix-Almendricos. Desde entonces la política ferroviaria a nivel nacional se ha centrado en la modernización de infraestructuras y en la apuesta por la Alta Velocidad y los servicios metropolitanos de cercanías (Albalate del Sol, Bel i Queralt, 2011).

\section{LA POLÍTICA DE FOMENTO DE LAS VÍAS VERDES}

Las políticas institucionales de recuperación de infraestructuras lineales en desuso dan comienzo en España en época tardía, a principios de los años noventa. Concretamente, el entonces Ministerio de Obras Públicas, Transportes y Medio Ambiente (MOPTMA) aprueba el Plan Tejido Verde, integrado en el Plan Director de Infraestructuras 1993-2007, con ese objetivo de recuperar y reutilizar como itinerarios de uso no motorizado una serie de recorridos históricos y dominios públicos (líneas férreas abandonadas, vías pecuarias, caminos de servicio de canales hidráulicos, caminos de sirga, recorridos de peregrinación, etc.).

En línea con este Plan Tejido Verde, dicho ministerio, en colaboración con RENFE y FEVE, encarga la redacción del inventario de líneas ferroviarias en desuso a la Fundación de los Ferrocarriles Españoles, punto de partida del Programa Vías Verdes que esta misma fundación impulsa con el fin de acondicionar las vías ferroviarias desmanteladas, infrautilizadas o que nunca llegaron a ponerse en servicio, para su utilización como itinerarios de uso no motorizado. Así, en 1993 se contabiliza un total de $5.764 \mathrm{~km}$ de líneas que ya no prestan servicio a lo largo de todo el recorrido español, considerando tan sólo las infraestructuras de titularidad pública estatal (propiedad de RENFE, FEVE u otros organismos estatales). Hasta entonces la longitud máxima que había alcanzado el ferrocarril español era de algo más de 18.000 $\mathrm{km}$, cifra que se alcanza en la década de los cincuenta. Por tanto, a principios de los noventa el $31,9 \%$ de todo lo que había sido la red ferroviaria pública se encuentra ya fuera de servicio.

Si al conjunto de estos trazados ferroviarios de titularidad pública estatal se le suman otras líneas consideradas en el anterior inventario (propiedad de organismos públicos regionales, locales y entidades privadas), la longitud total de las líneas españolas en desuso asciende a más de 7.600 km (Dirección General de Planificación Territorial, 1995).

Con todo este tejido ferroviario en estado de abandono como marco de referencia, en 1993 se inaugura la primera vía verde - la Vía Verde de la Sierra, entre las provincias de Cádiz y Sevilla-. El modelo de recuperación y gestión de las vías implica la coordinación interadministrativa entre organismos públicos a diferentes escalas: Si bien el propio ministerio impulsa con el programa de Vías Verdes la recuperación de las antiguas trazas ferroviarias, las tareas de conservación y gestión de los usos alternativos deben correr a cargo de un ente público regional o local, una sociedad o una fundación que asuma la responsabilidad sobre el trazado por medio de una concesión administrativa. Por tanto, la formulación del proyecto inicial, así como la gestión posterior, son desarrolladas por el organismo o la institución local 
interesada y, a su vez, la administración estatal se ocupa de las tareas de recuperación y restauración de la línea y sus infraestructuras anejas.

En 1996, con la disolución del antiguo MOPTMA y la creación del Ministerio de Medio Ambiente, el programa de Vías Verdes sufre algunas variaciones. De un lado, éste pasa a llamarse programa Caminos Naturales. Ello implica, a su vez, una mayor consideración de otros itinerarios naturales dentro del programa, no forzosamente relacionados con líneas férreas, como son las vías pecuarias, los caminos históricos, las vías de servidumbre de paso de los dominios públicos, etc. Esta ampliación del abanico de potenciales vías verdes se explica por la nueva vocación del Ministerio de Medio Ambiente, cuyas funciones dejan de estar vinculadas a la administración de las obras públicas y los transportes para ocuparse de aspectos ambientales más globales (Martín García, 2004). En la práctica, el trabajo de recuperar las antiguas líneas de ferrocarril y otros trazados naturales no se ve seriamente alterado, si bien la Fundación de los Ferrocarriles Españoles, encargada de coordinar a los actores implicados en el programa y a impulsar sus objetivos, se ve desplazada en sus tareas debido al divorcio original entre esta fundación y el nuevo ministerio.

En 2004 se recupera esta dinámica de colaboración, y se introduce la denominación final de Camino Natural-Vía Verde, para designar a las vías procedentes de antiguas líneas de ferrocarril, en comparación con el resto de caminos naturales, con otros orígenes (rutas históricas, vías pecuarias, etc.). Así, a finales de 2006 se encuentran en servicio $1.334 \mathrm{~km}$ de caminos naturales, de los que 884 corresponden a trazados ferroviarios, con una inversión de más de 55 millones de euros (Secretaría General para el Territorio y la Diversidad del Ministerio de Medio Ambiente, 2007). En 2010 estas cifras aumentan hasta los cerca de $1.800 \mathrm{~km}$ de vías verdes procedentes de trazados ferroviarios, con una inversión total acumulada de 110 millones de euros en acondicionamientos (Observatorio de Caminos Naturales e Itinerarios no Motorizados, 2011: 58).

\section{LAS VÍAS FÉRREAS DESMANTELADAS EN ANDALUCÍA: SITUACIÓN ACTUAL Y DIAGNÓSTICO}

Andalucía conserva en la actualidad una importante red de líneas ferroviarias desmanteladas y abandonadas, consecuencia, como se ha repasado anteriormente, del desarrollo histórico de las comunicaciones donde el tren adquiere un papel protagonista durante gran parte del siglo XIX y primera mitad del XX, rol que va perdiendo desde entonces.

El inventario de líneas ferroviarias susceptibles de usos alternativos que elabora la Dirección General de Planificación Territorial (1995) recoge un total de 41 líneas andaluzas en desuso — suponen $1.763 \mathrm{~km}$ de longitud - incluyendo trazados hoy desaparecidos, como los relativos a los tranvías interurbanos de Granada, aunque excluye bastantes líneas ferroviarias mineras de corto recorrido, principalmente en Huelva y Almería.

Tras una revisión detenida de esta base de datos, se hace necesario incorporar algunos tramos ferroviarios desmantelados pertenecientes a compañías mineras de 
capital privado, omitidas en el inventario original, que se centraba principalmente en líneas de titularidad pública. Asimismo, se han descartado aquellos trayectos que aún conservan tráfico funcional (caso de la línea Córdoba-Almorchón, de mercancías), así como las líneas y los trayectos de línea cuyo trazado físico - terraplén, explanación, surco... - haya desparecido por el avance del suelo urbano y la construcción. Buen ejemplo de ello son los mencionados tranvías interurbanos de Granada, que conectaban la capital con núcleos periféricos como Fuentevaqueros, Las Gavias, Pinos Puente o La Zubia, cuya huella sobre el territorio ha quedado desdibujada, cuando no sepultada, con la expansión y consolidación de la metrópolis granadina.

Figura 1. Mapa de las líneas férreas desmanteladas en Andalucía.

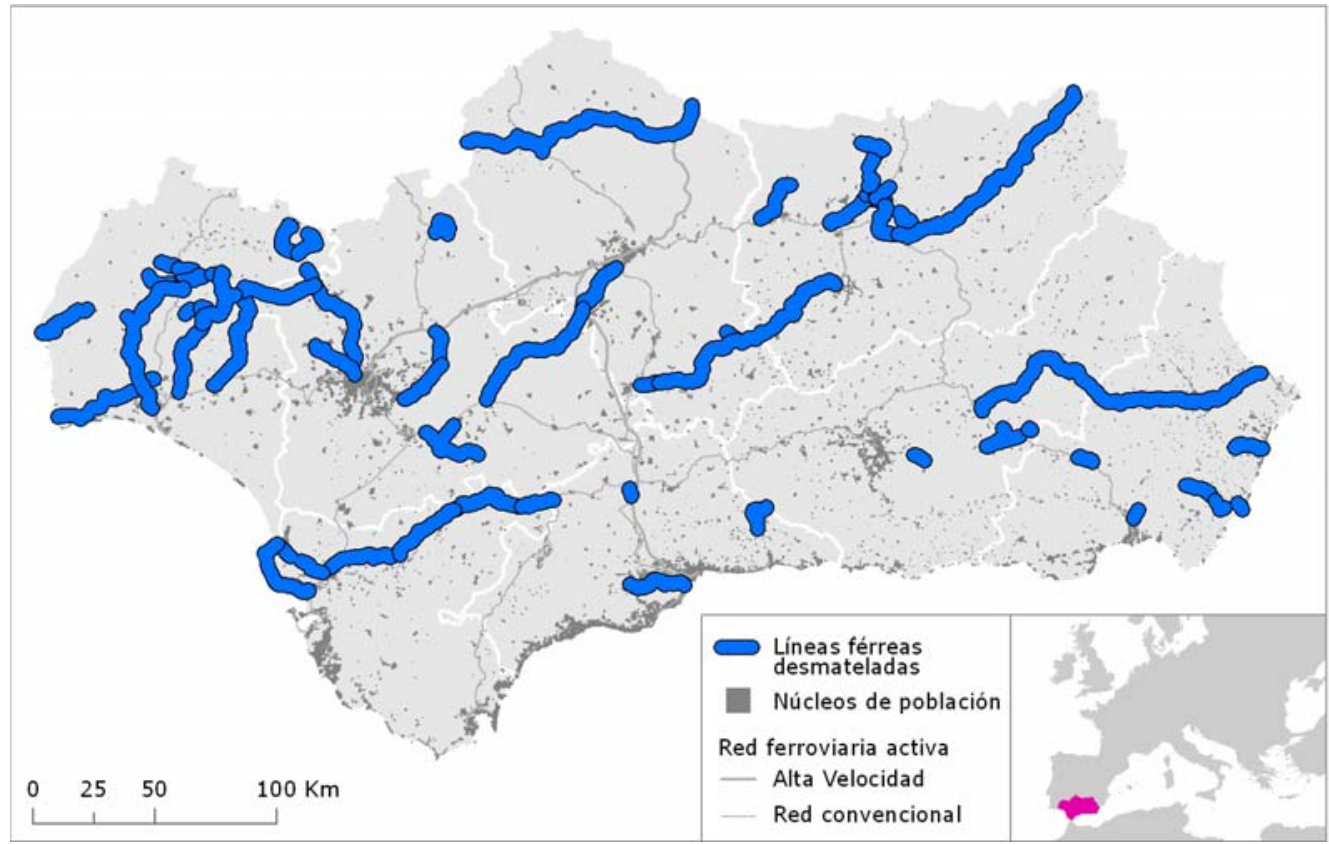

Fuente: Elaboración propia.

Así, esta revisión del inventario original incorpora un total de 49 líneas ferroviarias en desuso, con una longitud total de más de $1.600 \mathrm{~km}$, distribuidas por todo el territorio andaluz como muestra el mapa de la figura 1. Algunas de estas 49 líneas han sido divididas en varios tramos, dando como resultado un total de 57 segmentos (líneas completas o tramos), que forman una "aparente" red que servirá como punto de partida para los sucesivos análisis.

Este entramado de vías abandonadas coincide en muchos casos con el referido inventario del Ministerio de Obras Públicas, Transporte y Medio Ambiente. Para la incorporación de otras líneas se ha tomado como referencia la cartografía histórica y la actual, que permite hacer un análisis comparativo de la implantación primitiva de 
cada línea y su circunstancia presente. Así, existe un amplio abanico de situaciones en que se puede encontrar una línea sin uso, desde tramos que conservan en buena medida la infraestructura viaria (rieles, traviesas, balasto), tramos sin material viario pero con la explanación (trincheras, plataformas...), hasta el extremo opuesto de líneas que han sido convertidas en carretera.

Por tanto, debido a la variedad de condiciones en que se encuentra un antiguo trazado de ferrocarril, y la dificultad que surge de distinguir lo que aún se conserva de lo que no, resulta necesario establecer una serie de criterios para la consideración de una vía férrea que, aunque abandonada, aún se mantenga efectiva como vía. Así, los 49 itinerarios que componen el inventario modificado objeto de estudio siguen un criterio basado principalmente en la existencia y el mantenimiento de una senda o recorrido físico herencia del antiguo trazado, representado por la propia vía férrea, por la explanación resultante, por un camino testigo o excepcionalmente, por una pista o carretera que conserve la traza original de la vía. El criterio resulta relevante principalmente en aquellas líneas que presentan discontinuidades a lo largo del recorrido, alternando los tramos fácilmente reconocibles con los de trazado alterado, difuso o simplemente perdido.

Para la interpretación de los trazados actuales se ha recurrido al mapa topográfico de Andalucía a escala 1:10.000 (ediciones provinciales en formato ráster de 2001 y 2003), así como la Ortofotografía digital de Andalucía (vuelos de 2001-2002 y 2007), que se han contrastado con la cartografía histórica de las diferentes ediciones de Mapa Topográfico Nacional a escala 1:50.000. El ámbito temporal — casi todas las hojas tienen una edición de la primera mitad del siglo XX - y espacial del Mapa Topográfico Nacional hace posible explorar y reconocer líneas de ferrocarril cuyo testimonio ha sido borrado progresivamente con el tiempo resultando hoy difíciles de identificar sin acudir a la consulta de la cartografía antigua.

Esta red de infraestructuras ferroviarias desmanteladas se distribuye a lo largo del territorio andaluz como resultado de la lógica que explica la clausura del servicio de las diferentes líneas cerradas. Es por ello que el mayor número de kilómetros de vías desmanteladas se localiza en la provincia de Huelva, coincidiendo con la existencia de una intensa actividad minera en la franja pirítica del suroeste ibérico. Esta circunstancia también es aplicable a la región de Linares, que comparte con la anterior un próspero pasado minero del que hoy apenas quedan testimonios en activo, más allá de la rica herencia cultural y paisajística presente. Junto a estos dos casos emblemáticos existen muchas otras líneas de pequeño recorrido cuya función consistía en el transporte del mineral desde las explotaciones a las zonas portuarias o a los ejes ferroviarios regionales.

Junto al mineral, también determinados productos agrícolas pudieron motivar la implantación de líneas comerciales para conectar las zonas de producción con los nodos de exportación, hoy desaparecidas por la competencia del transporte rodado por carretera. Es el caso, por poner un ejemplo, de la vía férrea que conectaba Jerez de la Frontera con el embarcadero sanluqueño de Bonanza, con una clara vocación exportadora de los vinos de la comarca. 
Otra de los motivos que explica el abandono de líneas ferroviarias está causado por una política de clausura de líneas supuestamente deficitarias, que en muchos casos coinciden con ejes de articulación interior (dentro de Andalucía) o de conexión con otras comarcas limítrofes (Extremadura y Murcia). En estos casos destacan los dos ejes "oblicuos" del centro de Andalucía: las líneas Marchena-Valchillón y JaénCampo Real; la conexión Jerez-Almargen; así como los ejes exteriores de las líneas Utiel-Baeza y Guadix/Baza-Almendricos.

Todo ello permite poner de manifiesto la variedad de espacios, lugares y paisajes que en un tiempo quedaron conectados por medio de estos recorridos ferroviarios, cualidad que aún hoy preservan estas líneas desmanteladas dado que la infraestructura física que da soporte a la comunicación aún se mantiene sobre el territorio. Una evaluación del estado actual de conservación y uso de las vías férreas desmanteladas, junto con el grado de accesibilidad y proximidad a los centros de población permite conocer el potencial de utilización de las vías y la aportación que representan como ejes de articulación del espacio rural y de los núcleos urbanos dentro de un sistema de comunicaciones de uso no motorizado. Este estado de conservación y aptitud de uso también determina las posibilidades de ocio y recreo que la vía puede llegar a ofrecer. Junto a ello, la relevancia de la vía férrea y de las zonas que conecta y atraviesa, medida en términos de calidad ambiental, diversidad paisajística o importancia de patrimonio territorial (entendido como el que integra al patrimonio natural y cultural), proporciona el complemento para elaborar un diagnóstico con que estimar cada una de las cualidades y oportunidades de las distintas vías férreas desmanteladas en su nuevo panorama dentro de la ordenación territorial - ya sea como piezas del sistema relacional, del sistema de espacio libres o de ambos- - y el desarrollo económico local y regional.

\subsection{ANÁLISIS DE LA APTITUD DE USO: ADECUACIÓN PARA EL TRÁNSITO Y ACCESIBILIDAD}

La aptitud de uso es una cualidad propia de un trayecto para determinar su buen o mal estado físico de conservación, su adecuación para ser transitado y la proximidad o conectividad que tienen con respecto a los centros de población y las redes de transporte (ferrocarril o carretera). De manera sintética, este conjunto de variables evalúa la facilidad o dificultad para acceder y usar (es decir, recorrer) las vías férreas desmanteladas, bien como medios de comunicación no motorizado entre dos puntos, bien como itinerarios de ocio y disfrute al aire libre. Para ello, se han definido una serie de parámetros con que poder establecer de manera cuantitativa dicho nivel o grado de aptitud de uso de cada vía férrea desmantelada:

a) Estado de conservación y acondicionamiento de las vías, que distingue a cada vía por el buen estado físico de la explanación y la continuidad de su trazado original. En función de este parámetro se pueden distinguir desde las vías verdes como tales (acondicionadas o no acondicionadas), vías 
desmanteladas, pistas forestales o carreteras sobre antiguos trazados férreos, vías desdobladas, etc.

b) Proximidad a núcleos de población. En este caso, por medio de geoprocesos de proximidad de un software SIG se ha calculado la población que se encuentra a menos de 1.000 metros y también a menos de 5.000 metros de cada una de las vías férreas desmanteladas, excluyendo la población en diseminado. El uso de ambas distancias permite conocer la proximidad inmediata (1.000 metros) y relativa (5.000 metros) de la población a las vías férreas desmanteladas. También se justifica el uso de ambas cifras como manera de ponderar el diferente alcance de peatones y ciclistas en salvar distancias, entendiendo accesible a pie cualquier punto a menos de $1 \mathrm{~km}$ y accesible en bici cualquier punto a menos de $5 \mathrm{~km}$, por norma general.

c) Grado de interrelación con la red actual de ferrocarril. Esta variable mide las conexiones de la red actual de ferrocarril (explotada por RENFE) con las vías desmanteladas, como medio para desplazarse en tren hacia ellas. En algunos casos, las vías desmanteladas tienen como punto de origen (o destino) estaciones aún operativas, lo que les dota de mayores niveles de accesibilidad frente a otras vías abandonadas que han quedado "descolgadas" de la red de ferrocarril. En este caso hay que tener en cuenta que, dado que el ámbito de estudio queda restringido a la comunidad andaluza, no se han considerado los nodos exteriores de las vías desmanteladas que sobrepasan los límites autonómicos, como es el caso de las líneas Fuente del Arco-Peñarroya-Puertollano, Baeza-Utiel y GuadixAlmendricos. Así, se dan dos circunstancias: por una parte, líneas que presentan una conexión con la red ferroviaria en servicio, ya sea sobre la misma estación o apeadero, bien dentro del mismo núcleo urbano pero en dos puntos diferentes; por otro lado, se da el caso de líneas sin conexión con la red actual de ferrocarril.

Para un análisis de la accesibilidad a las vías desmanteladas resultaría fundamental acudir a la red de transportes por carretera, pero se entiende que hoy en día dicha infraestructura relacional se extiende de forma bastante homogénea por todo el territorio andaluz. Por ello resulta poco revelador utilizar esta red en el análisis de la accesibilidad de las vías desmanteladas, sin menosprecio de su papel actual como pilar del sistema de transportes en el territorio andaluz.

A cada uno de estos tres parámetros se les ha asociado un valor cuantitativo, con el fin de poder integrar las tres variables, de forma ponderada, en un único indicador que permita evaluar la accesibilidad y aptitud de uso de cada uno de los 57 segmentos de vía férrea desmantelada que forman el objeto de estudio. El cuadro de la figura 2 refleja los valores cuantitativos ponderados (puntuaciones) para cada uno de los parámetros anteriormente referidos.

Con este tipo de cuantificación, aquellas líneas desmanteladas que reúnen las máximas condiciones de accesibilidad y aptitud de uso obtendrían un valor de 100 . 
Por contra, el valor mínimo que una vía podría llegar a alcanzar es de 16. Las líneas han sido divididas en tramos o segmentos de línea debido a que presentan dos o más estados diferentes de conservación y acondicionamiento a lo largo del recorrido. Es el motivo que explica que las 49 líneas férreas objeto de estudio engloben hasta 57 secciones de vía (ya sean trayectos íntegros o partes de éstos).

Figura 2. Cuadro de las puntuaciones ponderadas de los parámetros que componen la aptitud de uso.

\begin{tabular}{|l|r|}
\hline \multicolumn{2}{|l|}{ PUNTUACIONES PONDERADAS DE LOS PARÁMETROS QUE COMPONEN LA APTITUD DE } \\
USO \\
\hline ESTADO DE CONSERVACIÓN Y ACONDICIONAMIENTO DE LAS VÍAS & Puntuación \\
\hline Vía Verde acondicionada & 40 \\
\hline Vía Verde no acondicionada & 32 \\
\hline Vía desmantelada / Vía desdoblada & 24 \\
\hline Vía desmantelada con problemas de discontinuidad & 16 \\
\hline Trazado ocupado por otro viario & 8 \\
\hline PROXIMIDAD A NÚCLEOS DE POBLACIÓN (I): POBLACIÓN A MENOS & Puntuación \\
\hline DE 1.000 METROS & 4 \\
\hline$<2.000$ habitantes & 8 \\
\hline $2.000<10.000$ habitantes & 12 \\
\hline $10.000<50.000$ habitantes & 16 \\
\hline $50.000<100.000$ habitantes & 20 \\
\hline$\geq 100.000$ habitantes & Puntuación \\
\hline PROXIMIDAD A NÚCLEOS DE POBLACIÓN (II): POBLACIÓN A MENOS \\
DE 5.000 METROS & 4 \\
\hline$<2.000$ habitantes & 8 \\
\hline $2.000<10.000$ habitantes & 12 \\
\hline $10.000<50.000$ habitantes & 16 \\
\hline $50.000<100.000$ habitantes & 20 \\
\hline$\geq 100.000$ habitantes & 20 \\
\hline GRADO DE INTERRELACIÓN CON LA RED ACTUAL DE FERROCARRIL & Puntuación \\
\hline Con conexión a la red actual de ferrocarril & \\
\hline Sin conexión & \\
\hline
\end{tabular}

Fuente: Elaboración propia. 
El resultado de aplicar dichos parámetros a la red viaria objeto de estudio queda reflejado en el mapa de aptitud de uso de las vías férreas desmanteladas de Andalucía (figura 3). Las vías férreas desmanteladas con mayores niveles de adecuación para el tránsito y accesibilidad se corresponden con líneas acondicionadas como vías verdes, con un importante volumen de población en el entorno y con una conexión con la red de ferrocarril de RENFE. Así, sobresale por encima de todas, la vía desmantelada Jaén-Campo Real (en toda el tramo comprendido entre Jaén y Navas del Selpillar, coincidiendo con la denominada Vía Verde del Aceite), con los mayores niveles de accesibilidad y calidad del tránsito. Con índices muy elevados también existen líneas con un origen de su recorrido en las inmediaciones de una aglomeración urbana o un centro regional, como en los casos de las líneas Marchena-Valchillón en su tramo cordobés (convertida en la Vía Verde de la Campiña), la línea Gibraleón-Ayamonte (Vía Verde del Litoral) o la línea Linares-San José-Baeza Empalme (Vía Verde de Linares). También se incluye en este grupo el pequeño segmento de la línea GuadixAlmendricos, correspondiente a la denominada Vía Verde del Almanzora.

Figura 3. Mapa de la aptitud de uso (adecuación para el tránsito y accesibilidad) de las vías férreas desmanteladas en Andalucía.

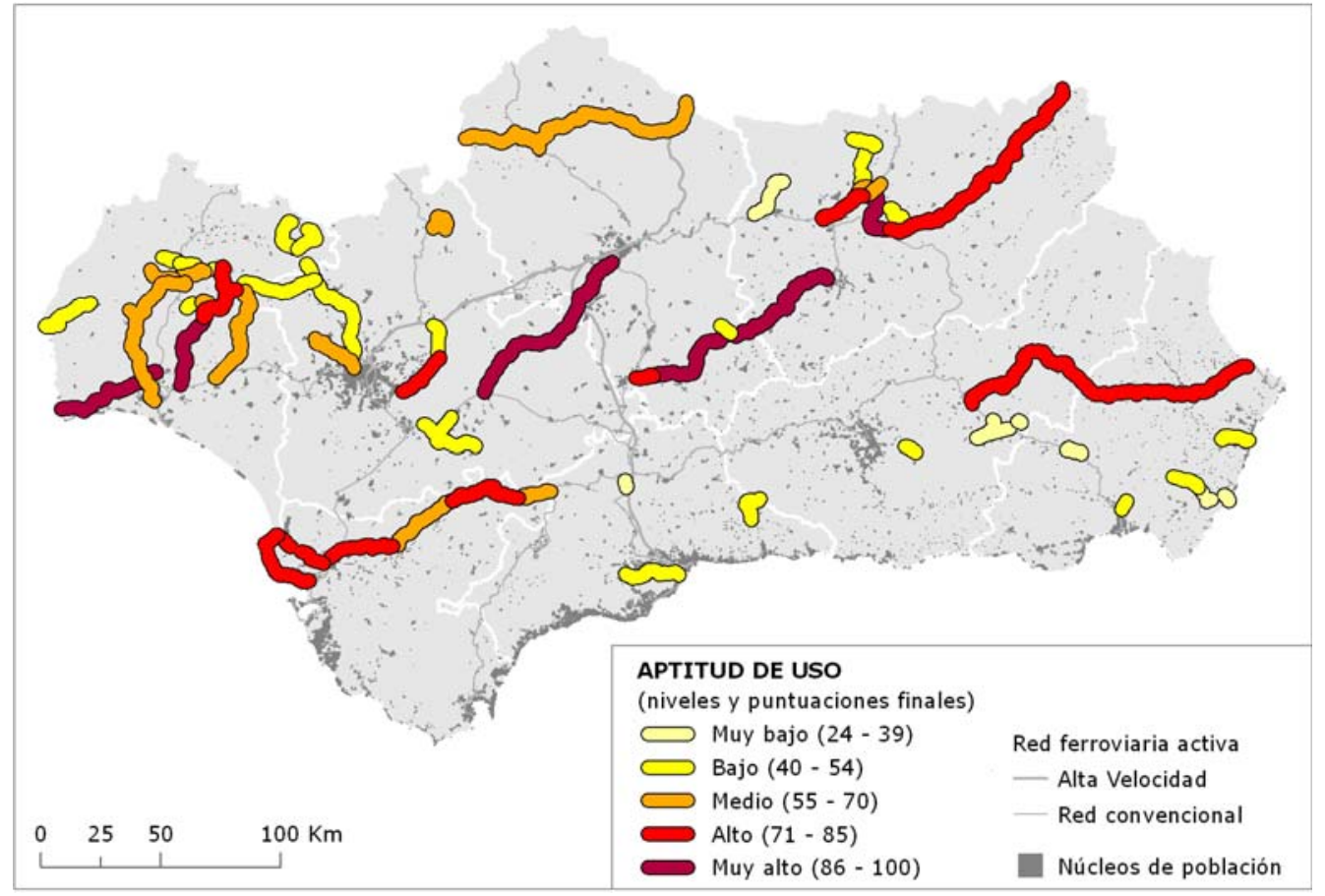

Fuente: Elaboración propia 
En el lado opuesto se encuentran las líneas con mayores problemas de accesibilidad y aptitud de uso, que coinciden con tramos bastante discontinuos, aislados de la red de transporte ferroviario y en zonas poco pobladas. Así, sobresalen las pequeñas líneas desmanteladas de la comarca del Marquesado y las Minas de Alquife (siendo la línea Hueneja-Minas de las Piletas el caso que menor índice de accesibilidad y aptitud de uso presenta). Asimismo destacan los tramos desdoblados de las líneas en funcionamiento Córdoba-Málaga y Linares-Almería, el segmento más fragmentado y discontinuo de la línea Lucainena de las Torres-Agua Amarga o el trazado abandonado del nonato servicio Marmolejo-Puertollano.

\subsection{ANÁLISIS DE LAS CUALIDADES AMBIENTALES Y PAISAJÍSTICAS}

Una vez que se han obtenido los valores relativos a la aptitud de uso de las vías férreas desmanteladas, es necesario estimar las cualidades ambientales y paisajísticas del entorno que atraviesan. Estas cualidades determinan la relevancia de uso de cada vía medida en términos de naturalidad y estado de conservación ambiental, riqueza y variedad paisajísticas, importancia de sus atributos culturales, etc. Esto condiciona a su vez el grado de aceptación social, que complementa el anterior análisis de la aptitud de uso. Para ello, se toman como referencia tres variables muy vinculadas como son la calidad ambiental, la calidad del paisaje inmediato y la cantidad de hitos patrimoniales junto a la vía:

a) La calidad ambiental se ha estimado calculando la proporción de vía férrea que coincide en su recorrido con algún espacio natural protegido (ENP). Para ello sólo se han considerado los espacios que componen la Red de Espacios Naturales Protegidos de Andalucía (RENPA) y los Planes Especiales de Protección del Medio Físico (PEPMF) de las ocho provincias. Asumiendo un excesivo ejercicio de simplificación, a todos estos espacios se les ha aplicado el mismo valor. Por tanto, una vía adopta el valor de calidad ambiental en función de la proporción de la longitud de su trazado que discurra por cualquier espacio natural protegido, sea de la tipología que sea. Una vía que discurra de forma íntegra por un espacio natural protegido obtiene una puntuación de 100 .

b) La calidad del paisaje inmediato se ha calculado en base a tres parámetros esenciales que miden la naturalidad, la riqueza y la diversidad de las unidades de paisaje que componen el espacio inmediato de las vías férreas desmanteladas, tal y como se entienden en el capítulo de paisaje del Informe de Medio Ambiente de Andalucía de 2006 (Consejería de Medio Ambiente, 2007). Para ello, se ha partido de las unidades fisionómicas de paisaje del Mapa de Paisajes de Andalucía (Moníz Sánchez, Moreira Madueño, Ojeda Rivera, Rodríguez Rodríguez, Rodríguez Suirán, Venegas Moreno, Zoido Naranjo, 2005), que divide la región en 34 tipos básicos de paisaje. Para este análisis se han seleccionado las unidades de paisaje comprendidas en un área de influencia de 100 metros a cada lado de las vías férreas 
desmanteladas. La calidad del paisaje inmediato se obtiene como resultado de ponderar a partes iguales los distintos índices de riqueza, naturalidad y diversidad:

Para el primer parámetro paisajístico, el de la naturalidad, se ha hecho necesario aplicar un valor cuantitativo discreto comprendido entre 1 y 4 a cada una de las unidades de paisaje, en función de su grado de naturalidad ambiental. El siguiente cuadro (figura 4) refleja la distribución de estos valores:

Figura 4. Cuadro de las puntuaciones ponderadas del criterio de naturalidad correspondiente a la variable de calidad del paisaje inmediato.

\begin{tabular}{|c|c|c|}
\hline $\begin{array}{l}\text { NIVELES DE } \\
\text { NATURALIDAD } \\
\text { PAISAJÍSTICA }\end{array}$ & UNIDADES FISIONÓMICAS DE PAISAJE & $\begin{array}{l}\text { PUNTUACIÓN } \\
\text { (PUNT. EN } \\
\text { BASE 100) }\end{array}$ \\
\hline \multirow{9}{*}{$\begin{array}{l}\text { Espacios naturales más } \\
\text { sobresalientes }\end{array}$} & Pinar, pinsapar y otros bosques de coníferas & \multirow{9}{*}{$\begin{array}{c}4 \\
(100)\end{array}$} \\
\hline & $\begin{array}{l}\text { Encinar, castañar, alcornocal y otros bosques de } \\
\text { frondosas }\end{array}$ & \\
\hline & Breñal arbolado & \\
\hline & Vegetación de ribera & \\
\hline & Dehesa & \\
\hline & Marisma natural y otros humedales & \\
\hline & Embalses y láminas de agua & \\
\hline & Playas & \\
\hline & Dunas y arenales & \\
\hline \multirow{13}{*}{$\begin{array}{l}\text { Espacios naturales menos } \\
\text { sobresalientes }\end{array}$} & Eucaliptal & \multirow{13}{*}{$\begin{array}{c}3 \\
(75)\end{array}$} \\
\hline & Breñal & \\
\hline & Espartizal & \\
\hline & Pastizal & \\
\hline & Erial & \\
\hline & Roquedales y neveros & \\
\hline & Terrenos volcánicos & \\
\hline & Acantilados & \\
\hline & Vegas & \\
\hline & Barrancos & \\
\hline & Malpaís & \\
\hline & Roquedales calizos & \\
\hline & Mesas y cuestas & \\
\hline
\end{tabular}




\begin{tabular}{|c|c|c|}
\hline $\begin{array}{c}\text { NIVELES DE } \\
\text { NATURALIDAD } \\
\text { PAISAJÍSTICA }\end{array}$ & UNIDADES FISIONÓMICAS DE PAISAJE & $\begin{array}{l}\text { PUNTUACIÓN } \\
\text { (PUNT. EN } \\
\text { BASE 100) }\end{array}$ \\
\hline & Deltas & \\
\hline \multirow{8}{*}{$\begin{array}{l}\text { Espacios agrícolas y } \\
\text { acuícolas }\end{array}$} & Olivar & \multirow{8}{*}{$\begin{array}{c}2 \\
(50)\end{array}$} \\
\hline & Almendrales y otras arboledas de secano & \\
\hline & Viñedos & \\
\hline & Tierra calma o de labor & \\
\hline & Frutales y otras arboledas en regadío & \\
\hline & Cultivos herbáceos en regadío & \\
\hline & Arrozal & \\
\hline & Salinas y cultivos acuícolas & \\
\hline \multirow{3}{*}{$\begin{array}{c}\text { Superficies } \\
\text { transformadas y alteradas }\end{array}$} & Urbano y periurbano & \multirow{3}{*}{$\begin{array}{c}1 \\
(25)\end{array}$} \\
\hline & Minas y escombreras & \\
\hline & Invernaderos & \\
\hline
\end{tabular}

Fuente: Elaboración propia.

De tal forma, la naturalidad paisajística de cada vía resulta de la ponderación de cada valor de naturalidad a partir de la superficie relativa que ocupan. Una vía que tan sólo atraviesa formaciones naturales (bosques, marismas, playas...) obtendría una calificación de 4 . Asimismo, una vía que surca a partes iguales formaciones naturales y espacios agrícolas (valores 4 y 2 respectivamente) obtiene una calificación de 3 .

El parámetro de riqueza es resultado de la suma de todas las unidades fisionómicas de paisaje comprendidas en el área de influencia de cada vía, de donde se ha elaborado un índice fruto de ponderar esta suma entre 34 (el numero total de unidades existentes en Andalucía). Así, una vía con un valor de riqueza igual a 100 sería aquella que atraviesa las 34 unidades de paisaje de Andalucía, cosa que no se da en la práctica. El valor mínimo de riqueza $(2,94)$ correspondería a una vía con una única unidad de paisaje, ejemplo que tampoco se da.

El índice de diversidad que se utiliza es el índice de Shannon, que indica el peso de cada unidad fisionómica de paisaje medida como proporción así como por su abundancia relativa. El índice también es sensible a cómo de iguales son las proporciones de distribución de las distintas unidades ${ }^{2}$. Los valores en el conjunto de estos tres parámetros paisajísticos (naturalidad, riqueza y diversidad) han sido normalizados y ponderados a partes iguales para poder integrarlos como una variable más en el resto del análisis ambiental y paisajístico.

${ }^{2}$ El índice de diversidad de Shannon se expresa con la siguiente fórmula:

I Shannon $=-\sum U i \ln U i$, donde $U i$ es la proporción de unidad fisionómica de paisaje tipo $i$. 
c) La importancia del patrimonio cultural se ha calculado a partir de los elementos cartográficos de patrimonio de los Datos Espaciales de Andalucía para Escalas Intermedias, DEA100 (Sistema Cartográfico de Andalucía, 2009). En concreto se han considerado todas aquellas zonas arqueológicas, conjuntos históricos y elementos históricos (yacimiento, castillo o torre y ermita) localizados a menos de 1.000 metros de una vía férrea desmantelada. Estos resultados se han normalizado de tal forma que el mayor caso observado (9 elementos patrimoniales) corresponde al valor 100 , mientras que el menor caso observado (ningún elemento patrimonial) corresponde al valor 0 .

Como resultado de todo este proceso de cuantificación y reducción de las distintas puntuaciones se obtiene tres índices correspondientes a los tres grandes atributos que conforman las cualidades ambientales y paisajísticas. Estos tres índices (que han sido normalizados para un rango teórico de 0 a 100) se han ponderado a partes iguales para obtener un último valor representativo.

Figura 5. Mapa de la calidad ambiental y paisajística de las vías férreas desmanteladas en Andalucía.

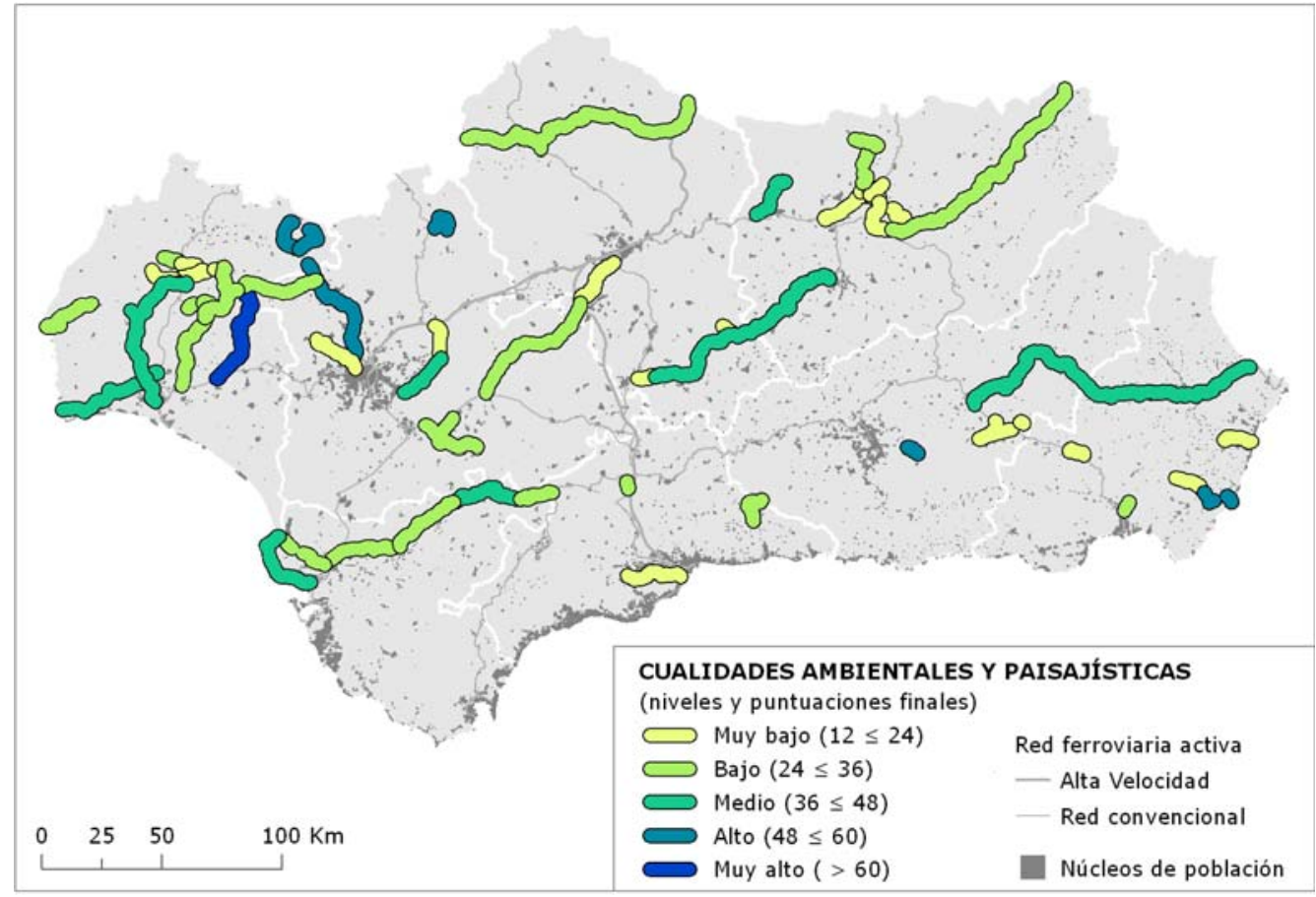

Fuente: Elaboración propia. 
El siguiente mapa recoge los niveles de calidad ambiental y paisajística de las vías férreas desmanteladas de Andalucía (figura 5). De la interpretación de estos datos se pueden extraer algunas conclusiones importantes. La vía férrea que mayores niveles de calidad ambiental y paisajística presenta es la línea Huelva-Río Tinto (puntuación ponderada de 62,06). Gran parte de esta línea, concretamente más de un $80 \%$, recorre el Paisaje Protegido de Río Tinto. En cuanto a la calidad del paisaje, esta vía ofrece niveles significativamente altos para los tres parámetros de riqueza, naturalidad y diversidad (puntuaciones antes de su ponderación de 16, 3,25 y 2,079, respectivamente). A su vez, existen 3 elementos significativos del patrimonio cultural alrededor de la vía.

La vía que más bajos niveles de calidad ambiental y paisajística alcanza es la compuesta por los dos ramales del ferrocarril del Marquesado y Minas de Alquife $(13,76)$. Entre ambas vías se localizan todas las demás, con una distribución muy variada de los niveles. Así, existen cuatro vías que discurren íntegramente por espacios naturales protegidos: la línea Zufre-Santa Olalla de Cala, la línea Estación de Cazalla y Constantina-Cerro del Hierro, la línea Granada-Sierra Nevada y la sección de la línea Guadix-Almendricos correspondiente a la denominada Vía Verde del Almanzora. También hay que destacar a la línea Jaén-Campo Real como la línea con mayores elementos significativos del patrimonio a su alrededor (un total de 9).

\subsection{INTEGRACIÓN DE LOS ANÁLISIS Y DIAGNÓSTICO DE LA CAPACIDAD POTENCIAL DE USO PÚBLICO Y DISFRUTE.}

De la intersección de los valores correspondientes a la aptitud de uso (adecuación para el tránsito y accesibilidad), por un lado, y los valores de las cualidades ambientales y paisajísticas, por otro, se puede elaborar un diagnóstico final, sintético, aunque válido para poder establecer una jerarquía o, cuanto menos, una orientación para la clasificación y la caracterización de las vías férreas desmanteladas que componen el mapa de los ferrocarriles abandonados de Andalucía.

Altos niveles de accesibilidad y altos niveles de calidad dan como resultado una vía óptima, muy adecuada para su uso público (en caso de que haya sido convertida en vía verde) o para su recuperación (caso de que aún se mantenga como mera vía férrea desmantelada sin actuación). Ello no debe restar importancia a vías que hayan obtenido un escaso nivel de potencialidad de uso, dado que, como se viene poniendo de manifiesto, una vía férrea desmantelada es siempre un bien, un activo compositivo del sistema de espacios libres o también del sistema relacional (dado que se tratan de ejes de comunicación de uso no motorizado), y son, como tales, piezas patrimoniales por sí mismas.

La siguiente matriz (figura 6), que combina mediante dos ejes cruzados los valores de aptitud de uso con los valores de calidad ambiental y paisajística, arroja nueve combinaciones resultantes, que reflejan la idoneidad y el potencial de cada vía para comportarse como una vía de uso público - tal y como ya lo hacen las vías verdes o algunas vías férreas desmanteladas-. En cualquier caso, los resultados que ofrece la matriz deben servir como tutelas orientadoras para identificar las vías férreas 
desmanteladas con mejores oportunidades de uso público y disfrute, siempre sobre la base de que todas ellas son válidas:

Figura 6. Matriz con el diagnóstico de la capacidad potencial de uso público y disfrute (a partir de los valores cruzados de aptitud de uso y cualidades ambientales y paisajísticas).

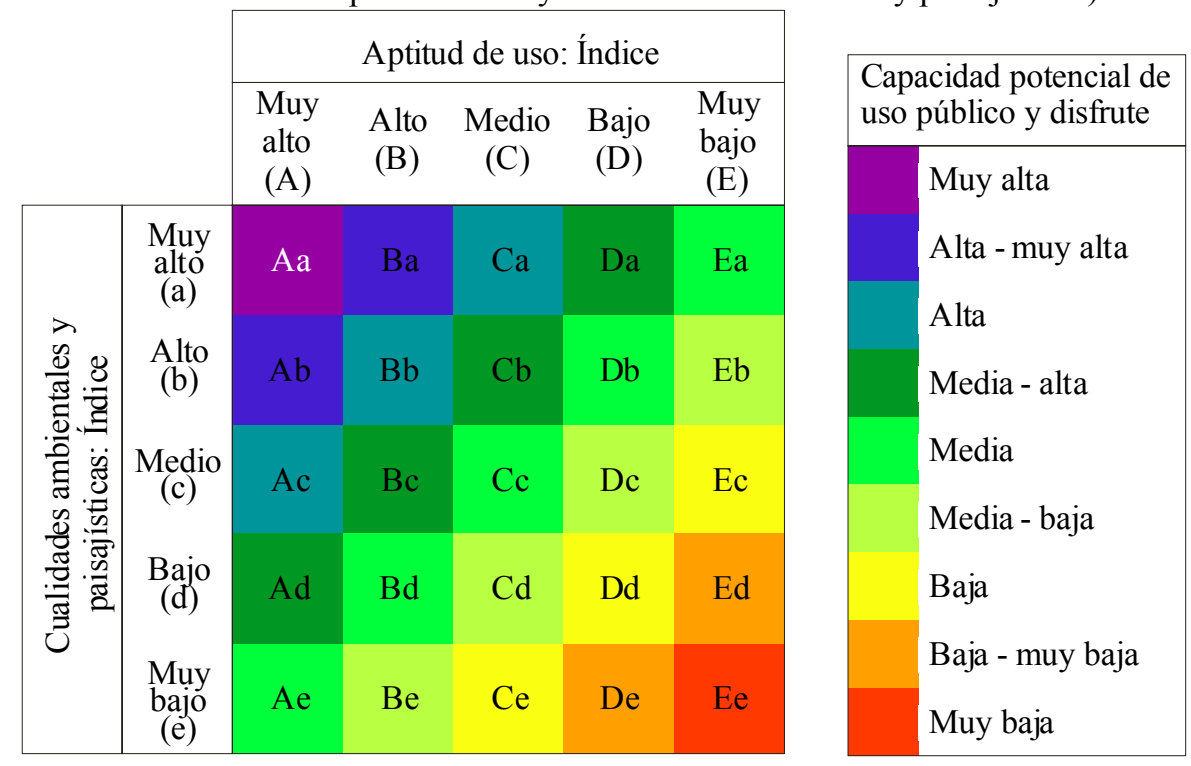

Fuente: Elaboración propia.

Los resultados de la combinación de los análisis de aptitud de uso y cualidades ambientales y paisajísticas, para cada una de las 57 líneas o sus segmentos, están recogidos en el anexo, por medio de un mapa con indicación de un código identificativo y un cuadro pormenorizado con los datos correspondientes.

De la aplicación de esta matriz no ha resultado ninguna vía con una capacidad potencial de uso muy alta (circunstancia que solo se daría con líneas bien transitables, muy bien conservadas, accesibles y con elevadas condiciones ambientales y paisajísticas). Por su parte, las vías férreas desmanteladas con una capacidad de uso alta y media-alta - considerablemente adecuadas - coinciden en gran medida con vías verdes acondicionadas, como son el caso de la Vía Verde del Aceite (Jaén), Vía Verde de la Sierra (Sevilla-Cádiz), la línea férrea Estación de Cazalla y ConstantinaCerro del Hierro (conocida como Vía Verde del Huéznar), etc. También se incluyen en esta categoría otras vías verdes no acondicionadas (Vía Verde del Litoral) y, lo que es más relevante, líneas ferroviarias desmanteladas que no llevan aparejadas ningún programa de recuperación y acondicionamiento, caso de la línea Puerto de Santa María-Sanlúcar de Barrameda, o los tramos no intervenidos de la línea GuadixAlmendricos (mayoritarios en esta antigua línea férrea). Los resultados de aplicar la matriz del diagnóstico quedan reflejados en el siguiente mapa (figura 7). 
Figura 7. Mapa del diagnóstico de la capacidad potencial de uso público y disfrute de las vías férreas desmanteladas de Andalucía.

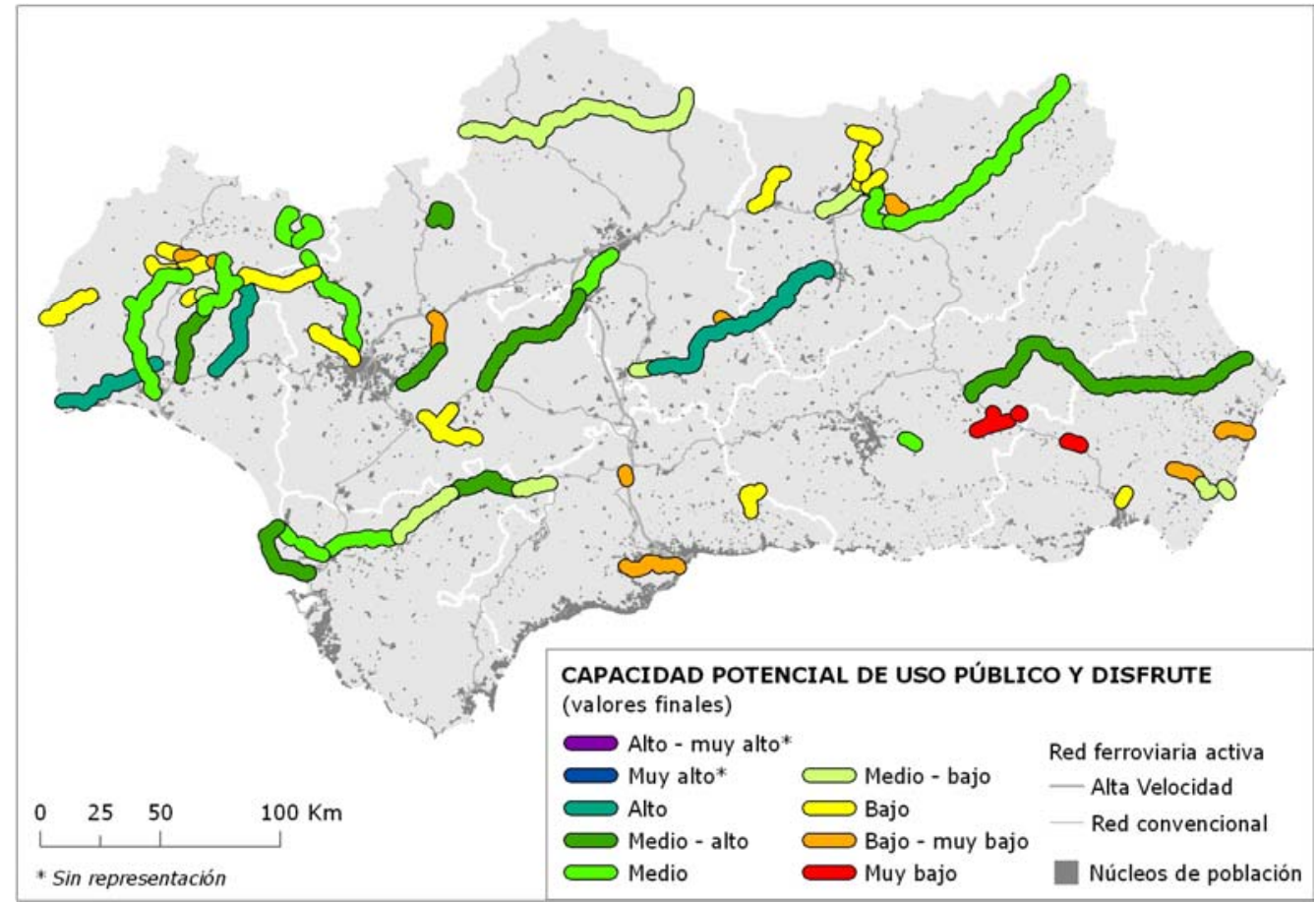

Fuente: Elaboración propia.

Con valores medios y bajos se encuentra la mayor parte de las líneas férreas desmanteladas de Andalucía, y tan solo son cuatro los casos de vías con un valor muy bajo de capacidad de uso - Estación del Cerro del Andévalo-Mina Perrunal, El Marquesado y Minas de Alquife, Estación de Hueneja-Mina de las Piletas y el trazado desdoblado en Nacimiento (Linares-Almería), que suman una longitud total de casi $40 \mathrm{~km}$-.

\section{CONCLUSIONES Y DISCUSIÓN}

La elaboración de un inventario propio de las líneas de ferrocarril desmanteladas en Andalucía tomando como partida el inventario que en su momento elaboró la Dirección General de Planificación Territorial (1995) ha dejado al descubierto una cantidad pequeña pero significativa de trazados y ramales secundarios no contemplados en el documento original. Estas líneas "menores" quedaban al margen del inventario oficial del ministerio, posiblemente por su carácter de líneas mineras e industriales periféricas, sobre las que RENFE, FEVE u otro organismo público no tenían competencias. Por otro lado, el inventario oficial incluye algunas líneas infrautilizadas pero aún operativas (caso de la línea Córdoba-Almorchón), así como 
las líneas de los tranvías interurbanos de Granada, de las que en la actualidad no se conserva ningún testimonio físico, ni siquiera la explanada.

El inventario propio desarrollado en este artículo de investigación perfecciona el oficial de 1995, dando cuenta de que en Andalucía existen cerca de $1.630 \mathrm{~km}$ de vías férreas desmanteladas, - frente a los $1.763 \mathrm{~km}$ que recoge el inventario de 1995 repartidos en 49 líneas o recorridos, algunos de ellos divididos en función de su diferente estado actual de conservación, hasta un total de 57 segmentos de líneas férreas.

A partir de ahí, se han estudiado diferentes parámetros que cualifican y condicionan la capacidad de uso público y disfrute de estas vías férreas desmanteladas como posibles itinerarios recuperados para uso no motorizado. La evaluación de estos parámetros — estado de adecuación de la vía, accesibilidad, calidad ambiental y paisajística... - ha dado como resultado un diagnóstico que permite establecer una escala de valores sobre un criterio definido y una prioridad de actuación de cara a la restauración de los trazados ferroviarios aún no intervenidos o al fomento y dinamización de los que ya hayan sido acondicionados como vías verdes. Hay que poner el énfasis en la idea aquí sostenida de que cada una de estas vías férreas desmanteladas contiene un valor intrínseco como trazas dibujadas sobre el territorio, lo que les confiere importantes cualidades por su capacidad de comunicar espacios separados, de aproximar áreas naturales y rurales y también porque encierran un patrimonio ferroviario digno de preservar. De hecho, cada nueva actuación encaminada a la recuperación y el fomento de estas vías férreas desmanteladas modificaría su estatus en el diagnóstico resultante. En ese sentido, la propia infraestructura debe ser entendida como un argumento principal en la cualificación del paisaje, por medio de sus componentes semánticos: elementos ferroviarios (y también mineros e industriales allá donde los haya) pero también su correspondiente discurso, un texto histórico y patrimonial alrededor de dichos elementos y del entorno circundante, por lo general de base agrícola y natural.

En definitiva, resulta necesario reconocer los esfuerzos que se han llevado a cabo desde la política pública de fomento de estos itinerarios no motorizados, política con más de 20 años de desarrollo. Sin embargo, como se pone de manifiesto en el diagnóstico de esta investigación, aún existen muchos desafíos por delante. Líneas como la que en su día conectaron a El Puerto de Santa María y Sanlúcar de Barrameda, tramos no intervenidos de la línea Guadix-Almendricos y otros muchos ejemplos de trazados aún no intervenidos conservan importantes potencialidades para su uso público como piezas integrantes del sistema relacional y de espacios libres. Piezas que ya funcionan adecuadamente en los casos de las vías recuperadas, las vías verdes.

\section{BIBLIOGRAFÍA}

ALBALATE DEL SOL, D.; BEL I QUERALT, G. (2011): Cuando la Economía no importa: auge y esplendor de la Alta Velocidad en España. En: Revista de Economía Aplicada, $\mathrm{n}^{\mathrm{o}}$ 55, vol XIX, pp. 171-190. 
CONSEJERÍA DE MEDIO AMBIENTE (2007): Medio Ambiente en Andalucía, Informe 2006. Consejería de Medio Ambiente, Junta de Andalucía, Sevilla.

DIRECCIÓN GENERAL DE PLANIFICACIÓN TERRITORIAL (1995): Líneas ferroviarias susceptibles de usos alternativos. Centro de Publicaciones del Ministerio de Obras Públicas, Transportes y Medio Ambiente, Madrid.

GARCÍA MARTÍN, M. (2009): Políticas públicas de fomento e implantación de redes de vías verdes: Algunas experiencias internacionales exitosas. En: Actas del $V$ Congreso Internacional de Ordenación del Territorio; 5th International Congress for Spatial Planning. Málaga, 22, 23 y 24 de noviembre de 2007, pp. 563-574.

MARTÍN GARCÍA, C.F. (2004): Programa de Caminos Naturales del Ministerio de Medio Ambiente. En: Ingeniería y Territorio, no 69, pp. 14-21.

MILLÁN RINCÓN, J. (2005): La implantación del ferrocarril en Andalucía. En: PH Boletín del Instituto Andaluz de Patrimonio Histórico, no 55, pp. 39-46.

MONÍZ SÁNCHEZ, C.; MOREIRA MADUEÑO, J.M.; OJEDA RIVERA, J.F.; RODRÍGUEZ RODRÍGUEZ, J.; RODRÍGUEZ SUIRÁN, M.; VENEGAS MORENO, M.; ZOIDO NARANJO, F. (2005): Los paisajes de Andalucía. En: Atlas de Andalucía, tomo II. Consejería de Medio Ambiente, Junta de Andalucía, Sevilla, pp. 221-240.

MORILLA CRITZ, J. (1999): Red ferroviaria, productos agrícolas y mercado regional en Andalucía (1860-1920). En: VIDAL OLIVARES, F.J.; MUÑOZ RUBIO, M.; SANZ FERNÁNDEZ, J.: Siglo y medio del ferrocarril en España, 1848 - 1998: economía, industria y sociedad. Instituto Alicantino Juan Gil-Albert, Alicante, pp. 495-516.

OBSERVATORIO DE CAMINOS NATURALES E ITINERARIOS NO MOTORIZADOS (2011): Estudio de la situación de los caminos naturales e itinerarios no motorizados en España. Ministerio de Medio Ambiente y Medio Rural y Marino, (s.l.). Disponible en Internet (última consulta 23/01/2014): http://www.magrama.gob.es/es/desarrollo-rural/temas/caminos-

naturales/Situaci\%C3\%B3n_Caminos_Naturales_e_Itinerarios_no_Motorizados_e n Espa $\%$ C3\%B1a tcm7-170627.pdf

PÉREZZ RAMÍREZ, B.; FUENTES RUIZ, M., (1997): Los transportes y las comunicaciones en Andalucía. En: Actas del I Congreso de Ciencia Regional de Andalucía : Andalucía en el umbral del siglo XXI. Jerez de la Frontera, 23-25 abril, pp. 623-637.

RAMOS MELERO, R. (2002): El futuro de la política ferroviaria en España. En: Boletín económico de ICE, Información Comercial Española, n² 2734, pp. 9-22.

RED NACIONAL DE LOS FERROCARRILES ESPAÑOLES (2007): Portal electrónico de RENFE. Disponible en Internet (última consulta 08/11/2007): http://www.renfe.es/empresa/historia/index.html

SISTEMA CARTOGRÁFICO DE ANDALUCÍA (2009): Datos espaciales de Andalucía para escalas intermedias. Escala 1:100.000. Junta de Andalucía, Sevilla. Soporte físico (DVD) y servicio WMS disponible en Internet (última consulta 18/01/2012): http://www.ideandalucia.es/wms/dea100? 


\section{ANEXO}

Mapa de las líneas férreas desmanteladas en Andalucía con indicación de un código identificativo.

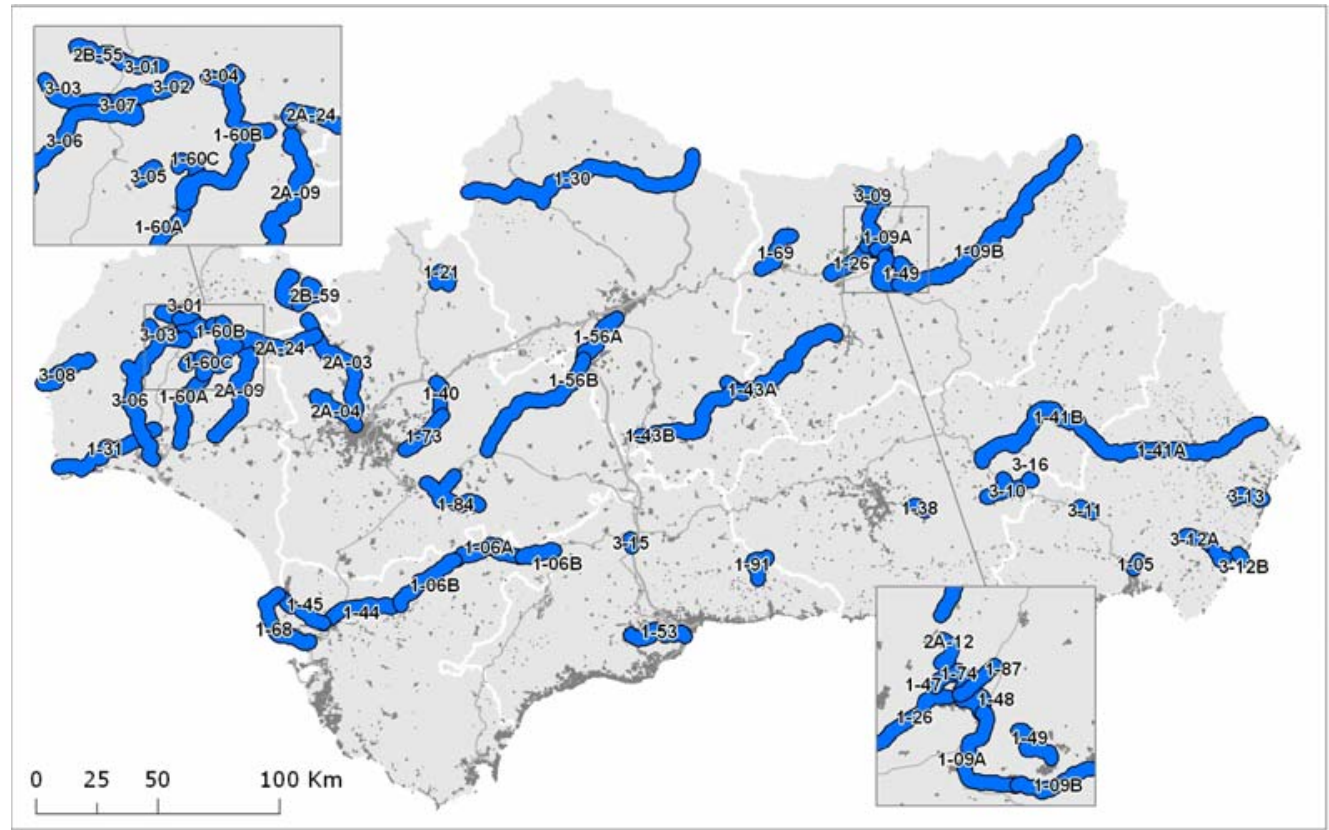

Fuente: elaboración propia

Cuadro de los valores correspondientes a los análisis de aptitud de uso, cualidades ambientales y paisajísticas y diagnóstico resultante para cada línea férrea desmantelada de Andalucía.

\begin{tabular}{|c|c|c|c|c|c|c|c|}
\hline $\begin{array}{l}\delta \\
\frac{0}{8} \\
0\end{array}$ & 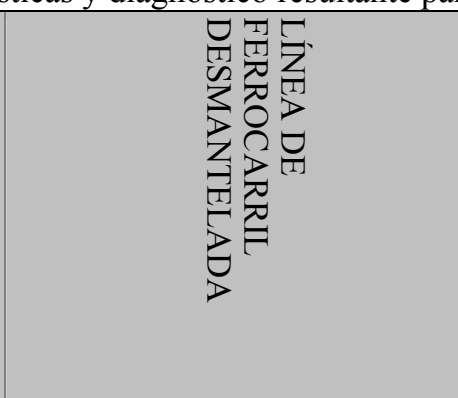 & 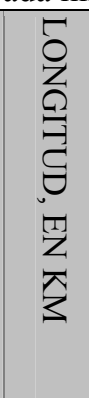 & 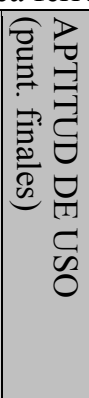 & 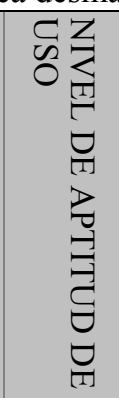 & 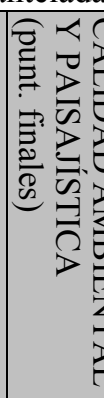 & 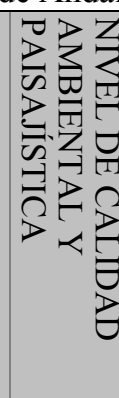 & 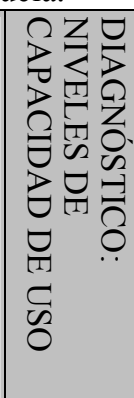 \\
\hline $1-05$ & Almería-El Chorrillo & 4,5 & 44 & Bajo & 28,01 & Bajo & Bajo \\
\hline $1-06 \mathrm{~A}$ & $\begin{array}{l}\text { Arcos de la Frontera-Almargen } \\
\text { (Vía Verde de la Sierra) }\end{array}$ & 36,2 & 72 & Alto & 41,54 & Alto & $\begin{array}{l}\text { Medio - } \\
\text { alto }\end{array}$ \\
\hline $1-06 \mathrm{~B}$ & $\begin{array}{l}\text { Arcos de la Frontera-Almargen } \\
\text { (tramos sin intervención) }\end{array}$ & 45,6 & 56 & Medio & 35,34 & Medio & $\begin{array}{l}\text { Medio - } \\
\text { bajo }\end{array}$ \\
\hline
\end{tabular}




\begin{tabular}{|c|c|c|c|c|c|c|c|}
\hline $\begin{array}{l}0 \\
0 \\
0 \\
0\end{array}$ & 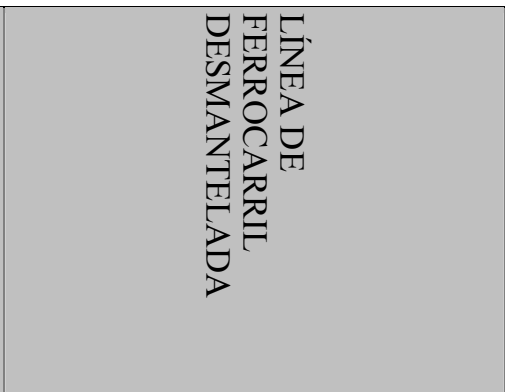 & 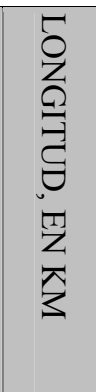 & 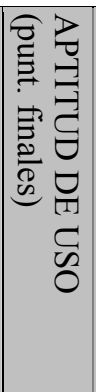 & 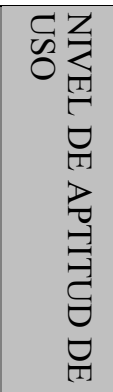 & 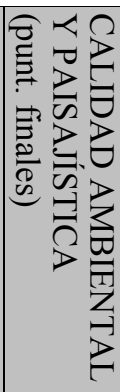 & 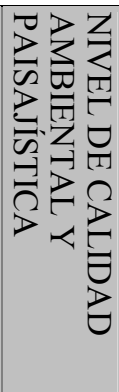 & 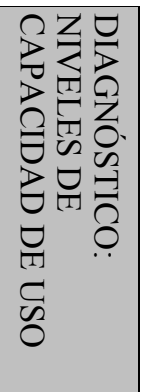 \\
\hline $1-09 A$ & $\begin{array}{l}\text { Baeza-Utiel (Vía Verde de Guada- } \\
\text { limar) }\end{array}$ & 21,4 & 88 & $\begin{array}{l}\text { Muy } \\
\text { alto }\end{array}$ & 21,40 & Bajo & Medio \\
\hline $1-09 B$ & $\begin{array}{l}\text { Baeza-Utiel (tramos sin interven- } \\
\text { ción) }\end{array}$ & 118,4 & 80 & Alto & 32,01 & Medio & Medio \\
\hline $1-21$ & $\begin{array}{l}\text { Estación de Cazalla y Constantina- } \\
\text { Cerro del Hierro }\end{array}$ & 15,1 & 68 & Medio & 59,64 & $\begin{array}{l}\text { Muy } \\
\text { alto }\end{array}$ & $\begin{array}{l}\text { Medio - } \\
\text { alto }\end{array}$ \\
\hline $1-26$ & Espeluy-Linares & 22,1 & 76 & Alto & 22,11 & Bajo & $\begin{array}{l}\text { Medio - } \\
\text { bajo }\end{array}$ \\
\hline $1-30$ & $\begin{array}{l}\text { Fuente del Arco-Peñarroya- } \\
\text { Puertollano }\end{array}$ & 129,1 & 56 & Medio & 31,46 & Medio & $\begin{array}{l}\text { Medio - } \\
\text { bajo }\end{array}$ \\
\hline $1-31$ & Gibraleón-Ayamonte & 49,0 & 92 & $\begin{array}{l}\text { Muy } \\
\text { alto }\end{array}$ & 39,19 & Medio & Alto \\
\hline $1-38$ & Granada-Sierra Nevada & 5,8 & 48 & Bajo & 54,88 & $\begin{array}{l}\text { Muy } \\
\text { alto }\end{array}$ & Medio \\
\hline $1-40$ & Guadajoz-Carmona Alta & 12,9 & 52 & Bajo & 19,97 & $\begin{array}{l}\text { Muy } \\
\text { bajo }\end{array}$ & $\begin{array}{l}\text { Bajo - } \\
\text { muy bajo }\end{array}$ \\
\hline $1-41 \mathrm{~A}$ & $\begin{array}{l}\text { Guadix-Almendricos (Vía Verde } \\
\text { del Almanzora) }\end{array}$ & 1,5 & 96 & $\begin{array}{l}\text { Muy } \\
\text { alto }\end{array}$ & 43,39 & Alto & Alto \\
\hline $1-41 B$ & $\begin{array}{l}\text { Guadix-Almendricos (tramos sin } \\
\text { intervención) }\end{array}$ & 154,5 & 80 & Alto & 43,60 & Alto & $\begin{array}{l}\text { Medio - } \\
\text { alto }\end{array}$ \\
\hline $1-43 \mathrm{~A}$ & $\begin{array}{l}\text { Jaén-Campo Real (Vía Verde del } \\
\text { Aceite) }\end{array}$ & 110,6 & 100 & $\begin{array}{l}\text { Muy } \\
\text { alto }\end{array}$ & 47,93 & Alto & Alto \\
\hline $1-43 B$ & $\begin{array}{l}\text { Jaén-Campo Real (tramos sin } \\
\text { intervención) }\end{array}$ & 8,2 & 84 & Alto & 14,50 & $\begin{array}{l}\text { Muy } \\
\text { bajo }\end{array}$ & $\begin{array}{l}\text { Medio - } \\
\text { bajo }\end{array}$ \\
\hline $1-44$ & $\begin{array}{l}\text { Jerez de la Frontera-Arcos de la } \\
\text { Frontera }\end{array}$ & 29,9 & 84 & Alto & 27,90 & Bajo & Medio \\
\hline $1-45$ & Jerez de la Frontera-Bonanza & 13,2 & 76 & Alto & 25,34 & Bajo & Medio \\
\hline $1-47$ & Linares-Los Salidos & 8,9 & 64 & Medio & 14,29 & $\begin{array}{l}\text { Muy } \\
\text { bajo }\end{array}$ & Bajo \\
\hline
\end{tabular}




\begin{tabular}{|c|c|c|c|c|c|c|c|}
\hline$\frac{0}{0}$ & 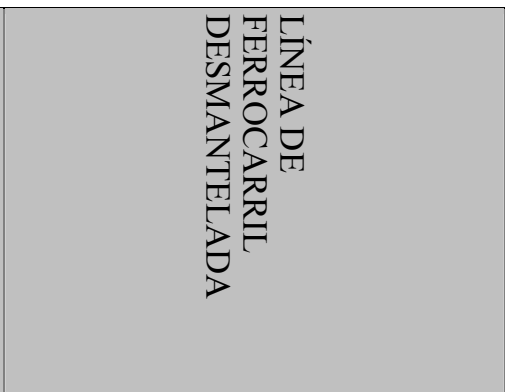 & 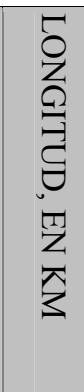 & 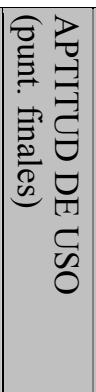 & 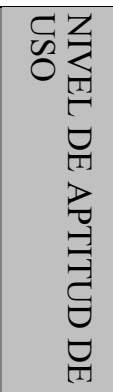 & 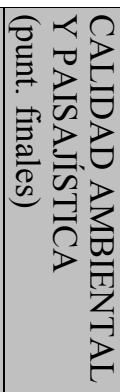 & 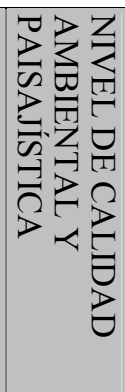 & 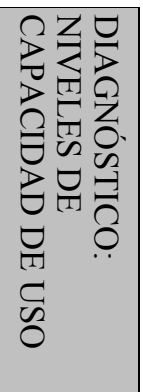 \\
\hline $1-48$ & Linares-San José-Baeza Empalme & 7,9 & 92 & $\begin{array}{l}\text { Muy } \\
\text { alto }\end{array}$ & 15,90 & $\begin{array}{l}\text { Muy } \\
\text { bajo }\end{array}$ & Medio \\
\hline $1-49$ & Linares-Úbeda-Baeza & 9,3 & 44 & Bajo & 16,44 & $\begin{array}{l}\text { Muy } \\
\text { bajo }\end{array}$ & $\begin{array}{l}\text { Bajo - } \\
\text { muy bajo }\end{array}$ \\
\hline $1-51$ & Luque-Baena & 4,7 & 40 & Bajo & 16,09 & $\begin{array}{l}\text { Muy } \\
\text { bajo }\end{array}$ & $\begin{array}{l}\text { Bajo - } \\
\text { muy bajo }\end{array}$ \\
\hline $1-53$ & Málaga-Coín & 27,2 & 44 & Bajo & 18,64 & $\begin{array}{l}\text { Muy } \\
\text { bajo }\end{array}$ & $\begin{array}{l}\text { Bajo - } \\
\text { muy bajo }\end{array}$ \\
\hline $1-56 \mathrm{~A}$ & $\begin{array}{l}\text { Marchena-Valchillón (provincia de } \\
\text { Córdoba) }\end{array}$ & 28,1 & 96 & $\begin{array}{l}\text { Muy } \\
\text { alto }\end{array}$ & 17,56 & $\begin{array}{l}\text { Muy } \\
\text { bajo }\end{array}$ & Medio \\
\hline $1-56 \mathrm{~B}$ & $\begin{array}{l}\text { Marchena-Valchillón (provincia de } \\
\text { Sevilla) }\end{array}$ & 60,1 & 88 & $\begin{array}{l}\text { Muy } \\
\text { alto }\end{array}$ & 32,04 & Medio & $\begin{array}{l}\text { Medio - } \\
\text { alto }\end{array}$ \\
\hline $1-60 A$ & $\begin{array}{l}\text { Mina Concepción-San Juan del } \\
\text { Puerto (de San Juan del Puerto a } \\
\text { Valverde) }\end{array}$ & 33,6 & 88 & $\begin{array}{l}\text { Muy } \\
\text { alto }\end{array}$ & 29,07 & Bajo & $\begin{array}{l}\text { Medio - } \\
\text { alto }\end{array}$ \\
\hline $1-60 \mathrm{~B}$ & $\begin{array}{l}\text { Mina Concepción-San Juan del } \\
\text { Puerto (de Valverde a Mina } \\
\text { Concepción) }\end{array}$ & 42,0 & 80 & Alto & 30,91 & Medio & Medio \\
\hline $1-60 \mathrm{C}$ & $\begin{array}{l}\text { Mina Concepción-San Juan del } \\
\text { Puerto (de Empalme a El Buitrón) }\end{array}$ & 6,8 & 56 & Medio & 24,95 & Bajo & $\begin{array}{l}\text { Medio - } \\
\text { bajo }\end{array}$ \\
\hline $1-68$ & $\begin{array}{l}\text { Puerto de Santa María-Sanlúcar de } \\
\text { Barrameda }\end{array}$ & 35,6 & 84 & Alto & 41,49 & Alto & $\begin{array}{l}\text { Medio - } \\
\text { alto }\end{array}$ \\
\hline $1-69$ & Puertollano-Marmolejo & 17,6 & 32 & $\begin{array}{l}\text { Muy } \\
\text { bajo }\end{array}$ & 46,51 & Alto & Bajo \\
\hline $1-73$ & $\begin{array}{l}\text { San Francisco de Guadaira- } \\
\text { Carmona Baja }\end{array}$ & 23,2 & 72 & Alto & 42,03 & Alto & $\begin{array}{l}\text { Medio - } \\
\text { alto }\end{array}$ \\
\hline $1-74$ & $\begin{array}{l}\text { San Roque-Linares-Baeza Empal- } \\
\text { me }\end{array}$ & 4,7 & 48 & Bajo & 15,34 & $\begin{array}{l}\text { Muy } \\
\text { bajo }\end{array}$ & $\begin{array}{l}\text { Bajo - } \\
\text { muy bajo }\end{array}$ \\
\hline $1-84$ & La Trinidad-Morón de la Frontera & 38,3 & 48 & Bajo & 24,72 & Bajo & Bajo \\
\hline $1-87$ & Vadollano-Linares & 7,5 & 64 & Medio & 23,56 & Bajo & Bajo \\
\hline
\end{tabular}




\begin{tabular}{|c|c|c|c|c|c|c|c|}
\hline$\stackrel{0}{0}$ & 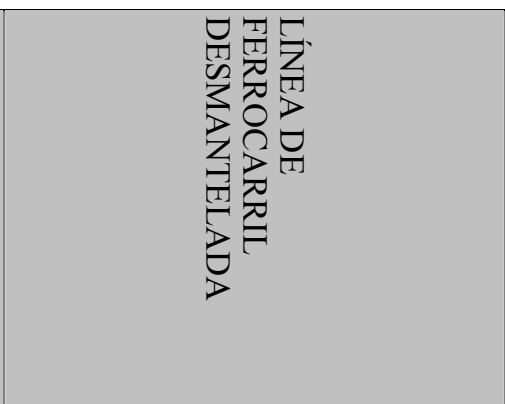 & 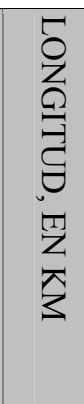 & 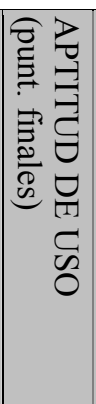 & 孚 & 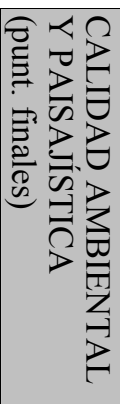 & 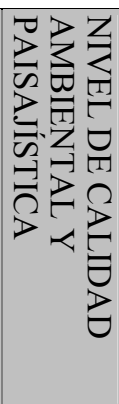 & 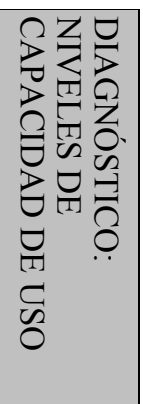 \\
\hline $1-91$ & Vélez Málaga-Ventas de Zafarraya & 18,1 & 40 & Bajo & 32,10 & Medio & Bajo \\
\hline $2 \mathrm{~A}-03$ & $\begin{array}{l}\text { San Juan de Aznalfarache-Minas } \\
\text { de Cala }\end{array}$ & 67,2 & 40 & Bajo & 59,00 & $\begin{array}{l}\text { Muy } \\
\text { alto }\end{array}$ & Medio \\
\hline $2 \mathrm{~A}-04$ & Camas-Aznalcóllar & 25,7 & 64 & Medio & 21,46 & Bajo & Bajo \\
\hline $2 \mathrm{~A}-09$ & Huelva-Río Tinto & 54,1 & 68 & Medio & 62,06 & $\begin{array}{l}\text { Muy } \\
\text { alto }\end{array}$ & Alto \\
\hline $2 \mathrm{~A}-12$ & Linares-La Carolina & 13,9 & 44 & Bajo & 27,71 & Bajo & Bajo \\
\hline $2 \mathrm{~A}-24$ & El Ronquillo-Peña del Hierro & 36,8 & 44 & Bajo & 32,45 & Medio & Bajo \\
\hline $2 B-55$ & Valdelamusa-San Telmo & 9,1 & 52 & Bajo & 29,43 & Bajo & Bajo \\
\hline $2 B-59$ & Zufre-Santa Olalla de Cala & 18,8 & 40 & Bajo & 56,23 & $\begin{array}{l}\text { Muy } \\
\text { alto }\end{array}$ & Medio \\
\hline $3-01$ & Valdelamusa-Cueva de la Mora & 8,0 & 52 & Bajo & 22,56 & Bajo & $\begin{array}{l}\text { Bajo - } \\
\text { muy bajo }\end{array}$ \\
\hline $3-02$ & El Tamujoso-Mina San Miguel & 17,7 & 56 & Medio & 22,03 & Bajo & Bajo \\
\hline $3-03$ & El Tamujoso-Mina la Joya & 13,5 & 60 & Medio & 23,48 & Bajo & Bajo \\
\hline $3-04$ & $\begin{array}{l}\text { Ramal de Mina de la Angostura y } \\
\text { Mina de la Esperanza (Mina } \\
\text { Concepción-San Juan del Puerto) }\end{array}$ & 4,4 & 52 & Bajo & 15,51 & $\begin{array}{l}\text { Muy } \\
\text { bajo }\end{array}$ & $\begin{array}{l}\text { Bajo - } \\
\text { muy bajo }\end{array}$ \\
\hline $3-05$ & El Cuervo-Mina Sotiel-Coronada & 3,8 & 52 & Bajo & 28,49 & Bajo & Bajo \\
\hline $3-06$ & $\begin{array}{l}\text { Tharsis-Río Odiel y Mina de la } \\
\text { Zarza }\end{array}$ & 78,9 & 64 & Medio & 36,71 & Medio & Medio \\
\hline $3-07$ & $\begin{array}{l}\text { Estación del Cerro del Andévalo- } \\
\text { Mina Perrunal }\end{array}$ & 3,1 & 36 & $\begin{array}{l}\text { Muy } \\
\text { bajo }\end{array}$ & 19,98 & $\begin{array}{l}\text { Muy } \\
\text { bajo }\end{array}$ & $\begin{array}{l}\text { Muy } \\
\text { bajo }\end{array}$ \\
\hline $3-08$ & Las Herrerías-Puerto de la Laja & 31,5 & 52 & Bajo & 27,20 & Bajo & Bajo \\
\hline $3-09$ & $\begin{array}{l}\text { La Carolina-Los Guindos-El } \\
\text { Centenillo }\end{array}$ & 14,1 & 48 & Bajo & 33,84 & Medio & Bajo \\
\hline $3-10$ & El Marquesado y Minas de Alquife & 26,1 & 36 & $\begin{array}{l}\text { Muy } \\
\text { bajo }\end{array}$ & 13,76 & $\begin{array}{l}\text { Muy } \\
\text { bajo }\end{array}$ & $\begin{array}{l}\text { Muy } \\
\text { bajo }\end{array}$ \\
\hline
\end{tabular}




\begin{tabular}{|c|c|c|c|c|c|c|c|}
\hline 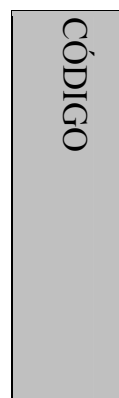 & 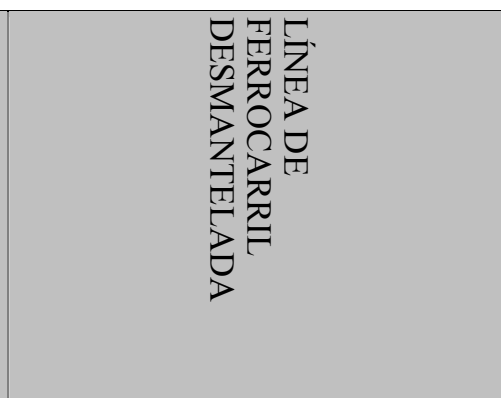 & $\begin{array}{l}5 \\
0 \\
2 \\
0 \\
3 \\
\vdots \\
0 \\
0 \\
Z \\
\pi \\
3\end{array}$ & 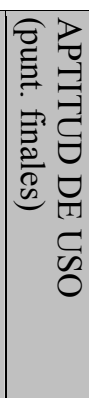 & 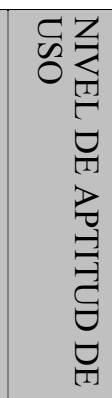 & 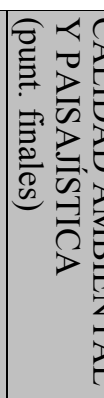 & 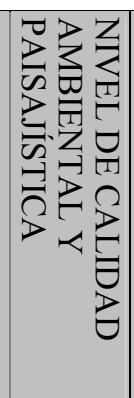 & 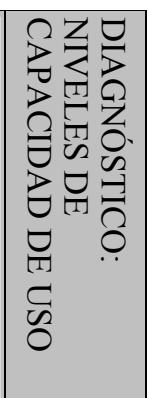 \\
\hline-11 & $\begin{array}{l}\text { Trazado desdoblado en Nacimien- } \\
\text { to (Linares-Almería) }\end{array}$ & 7,9 & 32 & $\begin{array}{l}\text { Muy } \\
\text { bajo }\end{array}$ & 20,10 & Bajo & $\begin{array}{l}\text { Muy } \\
\text { bajo }\end{array}$ \\
\hline$-12 \mathrm{~A}$ & $\begin{array}{l}\text { Lucainena de las Torres-Agua } \\
\text { Amarga (occidental) }\end{array}$ & 13,4 & 44 & Bajo & 21,93 & Bajo & $\begin{array}{l}\text { Bajo - } \\
\text { muy bajo }\end{array}$ \\
\hline $3-12 B$ & $\begin{array}{l}\text { Lucainena de las Torres-Agua } \\
\text { Amarga (orental) }\end{array}$ & 7,3 & 28 & $\begin{array}{l}\text { Muy } \\
\text { bajo }\end{array}$ & 50,34 & $\begin{array}{l}\text { Muy } \\
\text { alto }\end{array}$ & $\begin{array}{l}\text { Medio - } \\
\text { bajo }\end{array}$ \\
\hline $3-13$ & Bédar-Garrucha & 14,8 & 44 & Bajo & 20,27 & Bajo & $\begin{array}{l}\text { Bajo - } \\
\text { muy bajo }\end{array}$ \\
\hline $3-15$ & $\begin{array}{l}\text { Trazado desdoblado en el embalse } \\
\text { del Guadalhorce-Guadalteba } \\
\text { (Córdoba-Málaga) }\end{array}$ & 3,5 & 32 & $\begin{array}{l}\text { Muy } \\
\text { bajo }\end{array}$ & 24,49 & Bajo & $\begin{array}{l}\text { Bajo - } \\
\text { muy bajo }\end{array}$ \\
\hline $3-16$ & $\begin{array}{l}\text { Estación de Hueneja-Mina de las } \\
\text { Piletas }\end{array}$ & 2,5 & 24 & $\begin{array}{l}\text { Muy } \\
\text { bajo }\end{array}$ & 19,49 & $\begin{array}{l}\text { Muy } \\
\text { bajo }\end{array}$ & $\begin{array}{l}\text { Muy } \\
\text { bajo }\end{array}$ \\
\hline
\end{tabular}

Fuente: Elaboración propia. 